\title{
Short Communication \\ Correlates of anti-EBV EBNAI IgA positivity among unaffected relatives from nasopharyngeal carcinoma multiplex families
}

\author{
CM Chang*,', KJ Yu', WL Hsu',3, JM Major', JY Chen ${ }^{4}$, PJ Lou ${ }^{5}$, MY Liu', SR Diehl', AM Goldstein', \\ CJ Chen ${ }^{2,3}$ and A Hildesheim'
}

'Division of Cancer Epidemiology and Genetics, National Cancer Institute, NIH, DHHS, 6120 Executive Blvd., EPS 7073, Rockville, MD, USA; ${ }^{2}$ Graduate Institute of Epidemiology, College of Public Health, National Taiwan University, Taipei, Taiwan; ${ }^{3}$ Genomics Research Center, Academia Sinica, Taipei, Taiwan; ${ }^{4}$ National Institute of Cancer Research, National Health Research Institutes, 35, Keyan Road, Zhunan Town, Miaoli County 350, Taiwan; ${ }^{5}$ Department of Otolaryngology, National Taiwan University Hospital and National Taiwan University College of Medicine, Taipei, Taiwan; ${ }^{6}$ Center of General Education, National Taipei University of Nursing and Health Sciences, Taipei, Taiwan; ${ }^{7}$ Center for Pharmacogenomics and Complex Disease Research, New Jersey Dental School, University of Medicine and Dentistry of New Jersey, Newark, NJ, USA

BACKGROUND: To determine whether non-viral nasopharyngeal carcinoma (NPC) risk factors might be associated with (and mediated through) Epstein-Barr virus (EBV) serological responses linked to NPC risk, we evaluated predictors of risk of anti-EBNAI IgA seropositivity and other markers among unaffected relatives from a large NPC family study in Taiwan.

METHODS: Multivariate logistic regression conditioned on family was used to examine the associations between sociodemographic, dietary, lifestyle, and occupational variables and risk of anti-EBV EBNAI IgA positivity, anti-VCA IgA, and anti-DNase positivity. RESULTS: Among 2393 unaffected relatives from 319 multiplex families, II80 (49.3\%) were anti-EBV EBNAI IgA seropositive. None of the associations with anti-EBNAI IgA were statistically significant, except for being 31 -50 years of age (vs <30, adjusted ORs $0.5 \mathrm{I}-0.57$ ). For one or more EBV serological markers, there were suggestive associations for older age, GuangDong firm salted fish, betel use, current alcohol use, and male gender.

CONCLUSION: Overall, we found little evidence to suggest that non-viral NPC risk factors significantly alter EBV serological patterns, suggesting that non-viral NPC risk factors act through pathways independent of EBV serological responses.

British Journal of Cancer (2012) I 06, 206-209. doi:I0.1038/bjc.20II.502 www.bjcancer.com

Published online 17 November 201।

(c) 2012 Cancer Research UK

Keywords: Epstein-Barr virus; EBNA I; VCA; IgA; DNase; nasopharyngeal carcinoma

Nasopharyngeal carcinoma (NPC) is rare, albeit relatively common in southern China, southeast Asia, the Arctic, and North Africa (Chang and Adami, 2006). NPC risk factors include male gender, increased age, southern Chinese ethnicity, less education, consumption of salted fish and other preserved foods containing elevated levels of nitrate/nitrosamines, reduced fruit and vegetable consumption, cigarette smoking, betel nut chewing, alcohol consumption, and occupational exposures (Chang and Adami, 2006). Epstein-Barr virus (EBV), a ubiquitous herpesvirus that infects over $90 \%$ of adults worldwide, is believed to be necessary, but not sufficient for developing NPC (Chang and Adami, 2006). Longitudinal studies in China and Taiwan have shown that positivity for anti-EBNA1 IgA, anti-VCA IgA, and anti-DNase antibodies were associated with a significantly elevated NPC risk (Zeng et al, 1983, 1985; Chien et al, 2001; Ji et al, 2007; Hsu et al, 2009; Ng et al, 2010; Yu et al, 2011).

Whether non-viral risk factors act independently of anti-EBV serological responses or mediate EBV effects on NPC development is not known. To address this question, we evaluated the association between non-viral NPC risk factors and EBV

*Correspondence: Dr CM Chang; E-mail: changcm@mail.nih.gov Received 5 May 201 I; revised I September 201 I; accepted 22 October 20I I; published online 17 November 20 I I serological responses in a group of healthy individuals from high-risk NPC multiplex families in Taiwan.

\section{METHODS}

Participants in the present study were part of the NPC multiplex family study in Taiwan, previously described (Pickard et al, 2004; Yang et al, 2005; Yu et al, 2009). Over 300 NPC multiplex families were identified and recruited, including 659 NPC cases and 2557 unaffected parents, siblings, spouses, and children.

Risk factors were assessed by questionnaire for all individuals by a trained nurse. Sociodemographic characteristics were age, gender, ethnicity, and education. Lifestyle factors included smoking, betel use, and alcohol use. Occupational exposures evaluated included duration of formaldehyde exposure and wood exposure.

Dietary intake during ages 10-30 (representing consumption during adolescence and adulthood) was assessed by food frequency questionnaire, such as: consumption of salted fish, other preserved foods (salted meat, smoked foods, preserved eggs, fried/fermented bean curd, fermented rice, and fermented flour sauce), and fruits and vegetables. Other preserved foods were combined into a single variable by summing across the variables, and dividing into categories corresponding to the questionnaire diet frequency categories. 
Serum from participants was tested for the following EBV antibody markers: anti-VCA IgA by the immunofluorescent assay, anti-EBNA1 IgA by enzyme-linked immunosorbent assay, and anti-DNase by an enzyme neutralisation assay as previously described (Pickard et al, 2004). For the present analysis, a total of 2393 unaffected family members from 319 NPC multiplex families with data on EBV serology were included.

All estimates in this analysis were obtained using conditional logistic regression with the SAS PHREG procedure (SAS version 9.2), conditioning on families to account for familial correlations (Pfeiffer et al, 2003). We chose anti-EBNA1 IgA (at a cut-off of $\left.\mathrm{OD}_{405} \geqslant 0.10\right)$ as the primary outcome of interest for this analysis, because this measure was optimised for high sensitivity and most strongly predicted NPC risk in our family study (Yu et al, 2011). In secondary analyses, we evaluated (1) anti-EBNA1 IgA $\left(\mathrm{OD}_{405} \geqslant 0.20\right)$ with an alternative cut-off used for studies of sporadic NPC, (2) anti-VCA IgA based on the cut-off of $1: 10$ or greater dilution of serum, and (3) DNase neutralising activity, based on a cut-off optimised for high sensitivity in our family study (positivity cut-off $=160$ or more neutralising units; Yu et al, 2011). We also evaluated anti-EBNA1 IgA without the more ambiguous group $\left(0.10 \leqslant \mathrm{OD}_{405}<0.20\right)$, so that a clean, positive group $\left(\mathrm{OD}_{405} \geqslant 0.20\right)$ was compared with a clean, negative group $\left(\mathrm{OD}_{405}<0.10\right)$. However, the results resembled those of the original outcome $\left(\mathrm{OD}_{405} \geqslant 0.20\right.$ vs $\left.\mathrm{OD}_{405}<0.20\right)$, and therefore, were not presented.

Variables selected for consideration in the adjusted models were based on significant or borderline significant associations (based on the $95 \%$ confidence intervals (CI)) with EBNA1 positivity $\left(\mathrm{OD}_{405} \geqslant 0.10\right)$. Dose response was based on calculating overall Wald $P$-values for categorical variables.

\section{RESULTS}

There were a total of 2393 unaffected family members in this study. The mean age was 46 years ( 47 in women and 44 in men), and 53\% were women.

Overall, there were $1180(49.3 \%)$ individuals seropositive for anti-EBNA1 IgA $\left(\mathrm{OD}_{405} \geqslant 0.10\right)$. In the full model, being 31-40 years old and 41-50 years old ( $v s 18-30$ years) were inversely associated with anti-EBNA1 IgA positivity (adjusted OR

Table I Adjusted odds ratios (aORs) ${ }^{a}$ for the associations between NPC risk factors and risk of EBV antibody seropositivity for anti-EBNA IgA $\left(\mathrm{OD}_{405} \geqslant 0.1\right)$, anti-EBNA IgA $\left(\mathrm{OD}_{405} \geqslant 0.2\right)$, anti-VCA IgA $(\geqslant 1: 10)$, and anti-DNase $(\geqslant 160)$

\begin{tabular}{|c|c|c|c|c|c|c|c|c|c|c|c|c|c|c|c|c|}
\hline \multirow[b]{2}{*}{ Factor } & \multicolumn{4}{|c|}{$\begin{array}{c}\text { Anti-EBNAI } \\
\text { IgA-positive }(\geqslant 0.1)\end{array}$} & \multicolumn{4}{|c|}{$\begin{array}{c}\text { Anti-EBNAI } \\
\text { IgA-positive }(\geqslant 0.2)\end{array}$} & \multicolumn{4}{|c|}{$\begin{array}{c}\text { Anti-VCA } \\
\text { IgA-positive }(\geqslant I: 10)\end{array}$} & \multicolumn{4}{|c|}{$\begin{array}{c}\text { Anti-DNase-positive } \\
(\geqslant 160)\end{array}$} \\
\hline & Total & $\mathbf{N}$ & $\%$ & $\begin{array}{c}\text { aOR } \\
(95 \% \mathrm{CI})\end{array}$ & Total & $N$ & $\%$ & $\begin{array}{c}\text { aOR } \\
(95 \% \mathrm{CI})\end{array}$ & Total & $\mathbf{N}$ & $\%$ & $\begin{array}{c}\text { aOR } \\
(95 \% \mathrm{CI})\end{array}$ & Total & $N$ & $\%$ & $\begin{array}{c}\text { aOR } \\
(95 \% \mathrm{CI})\end{array}$ \\
\hline \multicolumn{17}{|l|}{ Age } \\
\hline $18-30$ & 429 & 216 & 50.4 & I.0 (Reference) & 429 & 64 & 14.9 & I.0 (Reference) & 307 & 66 & 21.5 & I.0 (Reference) & 429 & 99 & 23.1 & I.0 (Reference) \\
\hline $31-40$ & 558 & 250 & 44.8 & $0.5 \mathrm{I}(0.32,0.83)$ & 558 & 74 & 13.3 & $0.63(0.34,1.2)$ & 424 & 97 & 22.9 & I.I $(0.66,1.9)$ & 558 & 194 & 34.8 & $2.5(1.5,4.3)$ \\
\hline $41-50$ & 546 & 268 & 49.1 & $0.57(0.35,0.91)$ & 546 & 90 & 16.5 & $0.70(0.38,1.3)$ & 429 & 112 & 26.1 & $1.7(0.96,2.8)$ & 546 & 163 & 29.9 & $1.8(1.1,3.1)$ \\
\hline $51-60$ & 372 & 191 & 51.3 & $0.78(0.48,1.3)$ & 372 & 65 & 17.5 & $0.86(0.46,1.6)$ & 314 & 86 & 27.4 & $1.6(0.96,2.8)$ & 372 & 133 & 35.8 & $2.1(1.2,3.6)$ \\
\hline$>60$ & 488 & 255 & 52.3 & $0.77(0.45,1.3)$ & 488 & 91 & 18.7 & I.I $(0.58,2.2)$ & 390 & 130 & 33.3 & $1.9(1.1,3.5)$ & 488 & 178 & 36.5 & $1.8(1.0,3.3)$ \\
\hline P-trend & & & & 0.74 & & & & 0.18 & & & & 0.012 & & & & 0.81 \\
\hline \multicolumn{17}{|l|}{ Gender } \\
\hline Female & 1269 & 588 & 46.3 & I.0 (Reference) & 1269 & 187 & 14.7 & I.0 (Reference) & 994 & 275 & 27.7 & I.0 (Reference) & 1269 & 429 & 33.8 & I.0 (Reference) \\
\hline Male & 1124 & 592 & 52.7 & I.I $(0.73$, I.5) & 1124 & 197 & 17.5 & I.I $(0.68,1.7)$ & 870 & 216 & 24.8 & $0.81(0.54,1.2)$ & 1124 & 338 & 30.1 & $0.64(0.43,0.94)$ \\
\hline \multicolumn{17}{|l|}{ Smoking } \\
\hline Never & 1616 & 762 & 47.2 & I.0 (Reference) & 1616 & 235 & 14.5 & I.0 (Reference) & 1260 & 327 & 26.0 & I.0 (Reference) & 1616 & 514 & 31.8 & I.0 (Reference) \\
\hline Former & 186 & 105 & 56.5 & $1.7(0.91,3.0)$ & 186 & 43 & 23.1 & $1.4(0.71,2.8)$ & 148 & 39 & 26.4 & $0.98(0.52,1.9)$ & 186 & 59 & 31.7 & $0.66(0.35,1.3)$ \\
\hline Current & 585 & 310 & 53.0 & $0.95(0.63,1.4)$ & 585 & 104 & 17.8 & $0.97(0.58,1.6)$ & 450 & 123 & 27.3 & $1.3(0.86,2.1)$ & 585 & 192 & 32.8 & $1.5(0.97,2.3)$ \\
\hline \multicolumn{17}{|l|}{ Betel } \\
\hline Never & 2143 & 1033 & 48.2 & I.0 (Reference) & 2143 & 330 & 15.4 & I.0 (Reference) & 1669 & 436 & 26.1 & I.0 (Reference) & 2143 & 675 & 31.5 & I.0 (Reference) \\
\hline Former & 84 & 52 & 61.9 & $1.3(0.66,2.8)$ & 84 & 25 & 29.8 & $1.9(0.84,4.2)$ & 69 & 22 & 31.9 & $1.0(0.45,2.2)$ & 84 & 31 & 36.9 & $2.9(1.4,6.1)$ \\
\hline Current & 159 & 91 & 57.2 & I.3 $(0.72,2.4)$ & 159 & 27 & 17.0 & I.I $(0.51,2.4)$ & 119 & 31 & 26.1 & $0.77(0.39,1.5)$ & 159 & 58 & 36.5 & $2.2(1.2,4.2)$ \\
\hline \multicolumn{17}{|l|}{ Alcohol } \\
\hline Never & 1818 & 873 & 48.0 & I.0 (Reference) & 1818 & 272 & 15.0 & I.0 (Reference) & 1409 & 374 & 26.5 & I.0 (Reference) & 1818 & 584 & 32.1 & I.0 (Reference) \\
\hline Former & 100 & 56 & 56.0 & $0.8(0.36,1.6)$ & 100 & 23 & 23.0 & $0.7(0.28,1.8)$ & 81 & 18 & 22.2 & $0.62(0.28,1.4)$ & 100 & 33 & 33.0 & $0.68(0.32,1.5)$ \\
\hline Current & 469 & 248 & 52.9 & I.I $(0.77,1.7)$ & 469 & 87 & 18.6 & $1.7(1.0,2.8)$ & 368 & 97 & 26.4 & I.I $(0.74,1.7)$ & 469 & 148 & 31.6 & $1.2(0.82,1.9)$ \\
\hline \multicolumn{17}{|l|}{ Duration of formaldehyde } \\
\hline None & 1042 & 484 & 46.5 & I.0 (Reference) & 1042 & 182 & 17.5 & I.0 (Reference) & 1042 & 301 & 28.9 & I.0 (Reference) & 1042 & 382 & 36.7 & I.0 (Reference) \\
\hline$<10$ years & 155 & 7I & 45.8 & $1.3(0.84,2.0)$ & 155 & 18 & 11.6 & $0.78(0.42,1.5)$ & 155 & 36 & 23.2 & $0.77(0.48,1.3)$ & 155 & 58 & 37.4 & I.I $(0.71,1.7)$ \\
\hline$\geqslant 10$ years & 216 & 122 & 56.5 & $1.3(0.84,2.0)$ & 216 & 53 & 24.5 & $1.4(0.83,2.4)$ & 216 & 81 & 37.5 & I.I $(0.67,1.7)$ & 216 & 81 & 37.5 & $1.1(0.67,1.6)$ \\
\hline$P$-trend & & & & 0.14 & & & & 0.25 & & & & 0.87 & & & & 0.78 \\
\hline \multicolumn{17}{|l|}{ Fruits and vegetables } \\
\hline Less than once a day & 257 & 142 & 55.3 & I.0 (Reference) & 257 & 47 & 18.3 & I.0 (Reference) & 194 & 51 & 26.3 & I.0 (Reference) & 257 & 93 & 36.2 & I.0 (Reference) \\
\hline I-2 times a day & 1324 & 645 & 48.7 & $0.88(0.54,1.4)$ & 1324 & 202 & 15.3 & $0.98(0.53,1.8)$ & 1025 & 269 & 26.2 & $0.86(0.5 \mathrm{I}, \mathrm{I} .5)$ & 1324 & $4 \mid 1$ & 31.0 & $0.69(0.42,1.1)$ \\
\hline 2 or more times a day & 784 & 377 & 48.1 & $0.86(0.5 \mathrm{I}, \mathrm{I} .5)$ & 784 & 128 & 16.3 & $0.86(0.45,1.6)$ & 622 & 162 & 26.1 & $0.95(0.54,1.7)$ & 784 & 248 & 31.6 & $0.80(0.47,1.4)$ \\
\hline P-trend & & & & 0.62 & & & & 0.46 & & & & 0.99 & & & & 0.68 \\
\hline \multicolumn{17}{|l|}{ GuangDong salted fish } \\
\hline Never & 1941 & 960 & 49.5 & I.0 (Reference) & 1941 & 300 & 15.5 & I.0 (Reference) & 1474 & 410 & 27.8 & I.0 (Reference) & 1941 & 610 & 31.4 & I.0 (Reference) \\
\hline Mouldy fragrant fish only & 45 & 23 & 51.1 & $1.4(0.58,3.3)$ & 45 & 6 & 13.3 & $0.78(0.22,2.7)$ & 42 & 10 & 23.8 & $1.0(0.38,2.7)$ & 45 & 15 & 33.3 & $0.76(0.31,1.9)$ \\
\hline Firm fish only & 60 & 36 & 60.0 & $1.8(0.86,3.9)$ & 60 & 14 & 23.3 & $1.6(0.58,4.2)$ & 57 & 18 & 31.6 & $2.0(0.88,4.5)$ & 60 & 25 & 41.7 & $2.7(1.1,6.5)$ \\
\hline Both mouldy and firm fish & 98 & 40 & 40.8 & $0.98(0.51,1.9)$ & 98 & 24 & 24.5 & $1.9(0.85,4.3)$ & 90 & 14 & 15.6 & $0.84(0.40,1.8)$ & 98 & 35 & 35.7 & $1.3(0.7,2.5)$ \\
\hline
\end{tabular}

${ }^{a}$ Adjusted odds ratios are from full models containing the following variables: age, gender, smoking, betel use, alcohol use, duration of formaldehyde exposure, fruit and vegetable intake, and type of salted fish intake. 
$(\mathrm{aOR})=0.51, \quad 95 \% \quad \mathrm{CI}=0.32-0.83 \quad$ and $\quad \mathrm{aOR}=0.57, \quad 95 \%$ $\mathrm{CI}=0.35-0.91$, respectively), but associations with the older age groups were not significant. There was a suggestive, nonsignificant association between GuangDong firm salted fish ( $v s$ never; $\mathrm{aOR}=1.8$ ) and anti-EBNA1 positivity (Table 1 ).

A total of $384(16.1 \%)$ individuals were seropositive for anti-EBNA1 IgA $\left(\mathrm{OD}_{405} \geqslant 0.20\right)$. Current alcohol use ( $v s$ never use) was associated with anti-EBNA1 IgA positivity $(\mathrm{aOR}=1.7$, $95 \% \mathrm{CI}=1.0-2.8$; Table 1). Former betel use ( $v s$ never use; $\mathrm{aOR}=1.9$ ) and GuangDong firm salted fish, and both mouldy and firm salted fish ( $v s$ never; aORs 1.6-1.9) were nonsignificantly associated with anti-EBNA1 IgA positivity. There were nonsignificantly inverse associations with anti-EBNA1 IgA positivity for the three middle age groups $(31-40,41-50$, and $51-60$ years; aORs $0.63-0.86$ ), but no association with the oldest age group (Table 1).

A total of 491 (26.3\%) individuals were seropositive for anti-VCA IgA. Compared with the youngest age group (less than 30 ), the oldest age group (greater than $60 ; \mathrm{aOR}=1.9,95 \%$ $\mathrm{CI}=1.1-3.5) \quad$ was associated with anti-VCA IgA positivity $(P$-trend $=0.012)$. Not reaching statistical significance, GuangDong firm salted fish ( $v s$ never; $\mathrm{aOR}=2.0,95 \% \mathrm{CI}=0.88-4.5)$ was associated with anti-VCA IgA positivity (Table 1 ).

A total of $767(32.1 \%)$ individuals were seropositive for anti-DNase. Former and current betel use ( $v s$ never use) and GuangDong firm salted fish ( $v s$ never) were significantly associated with anti-DNase seropositivity (aORs 2.2-2.9). Males were at lowered risk of anti-DNase seropositivity compared with females $(\mathrm{aOR}=0.64,95 \% \mathrm{CI}=0.43-0.94)$. Age greater than 30 ( $v s$ less than 30 ) was associated with anti-DNase seropositivity (aORs 1.8-2.5, $P$-trend $=0.81$ ).

\section{DISCUSSION}

With a couple of notable exceptions discussed below, we saw little evidence to indicate that non-viral NPC risk factors influence anti-EBV seroreactivity. This suggests that non-viral NPC risk factors are unlikely to influence NPC risk by altering anti-EBV serological profiles.

We observed a U-shaped curve for age, with anti-EBNA1 IgA positivity being higher among the youngest and oldest, and lower among the middle age categories. The higher antibody positivity rate observed among older individuals, also seen for anti-VCA IgA, could reflect immunosenescence in older age, leading to more frequent viral lytic reactivation (Agarwal and Busse, 2010). The fact that anti-EBNA1 IgA positivity, but not other markers, was also higher among the youngsters, is not clearly understood.

There was a suggestive elevated risk for all EBV markers (aORs 1.6-2.7) associated with GuangDong firm salted fish, but not

\section{REFERENCES}

Agarwal S, Busse PJ (2010) Innate and adaptive immunosenescence. Ann Allergy Asthma Immunol 104(3): 183-190; quiz 190-2, 210

Chang ET, Adami HO (2006) The enigmatic epidemiology of nasopharyngeal carcinoma. Cancer Epidemiol Biomarkers Prev 15(10): 1765- 1777

Chang MC, Chiang CP, Lin CL, Lee JJ, Hahn LJ, Jeng JH (2005) Cell-mediated immunity and head and neck cancer: with special emphasis on betel quid chewing habit. Oral Oncol 41(8): 757-775

Chien YC, Chen JY, Liu MY, Yang HI, Hsu MM, Chen CJ, Yang CS (2001) Serologic markers of Epstein-Barr virus infection and nasopharyngeal carcinoma in Taiwanese men. $N$ Engl J Med 345(26): 1877-1882

Hsu WL, Chen JY, Chien YC, Liu MY, You SL, Hsu MM, Yang CS, Chen CJ (2009) Independent effect of EBV and cigarette smoking on nasopharyngeal carcinoma: a 20-year follow-up study on 9,622 males without family history in Taiwan. Cancer Epidemiol Biomarkers Prev 18(4): $1218-1226$ mouldy fragrant fish. In an in vitro study, aqueous extracts of Cantonese salted fish activated EBV lytic replication in Raji cells in a dose-dependent manner by causing cells to express EBV early antigen (Shao et al, 1988). However, it is unclear why one type of GuangDong salted fish would activate EBV, but not another type.

A significant association was observed between betel use and anti-DNase positivity, and was suggestive for anti-EBNA1. Although betel nut use is classified as a group 1 carcinogen in humans, there is no data on whether or not betel use can lead to EBV reactivation (IARC, 2004). Betel nut ingredients have induced inflammation in vitro, supporting the biological plausibility of this association (Jeng et al, 2000, 2003; Chang et al, 2005).

There may be recall bias of diet between the ages of 10-30, such that young subjects may be prone to recall their diet in adolescence and older subjects prone to recall diet in their adulthood. EBV serology was measured at only one point in time and may not capture all episodes of EBV lytic replication. We would not have detected associations with other aspects of EBV exposure and/or host response to EBV. Our results may have been affected by the reproducibility for anti-VCA IgA testing, which was modest (agreement $\sim 68 \%, \kappa \sim 0.29-0.38$; Pickard et al, 2004). Our findings for a high-risk population may not represent that of the general population, and associations may be attenuated due to similarity of exposures within high-risk families (Yang et al, 2005). However, by studying unaffected relatives from NPC multiplex families, the population is enriched in terms of EBV IgA antibody positivity, which occurs at much lower frequencies in the general population (Pickard et al, 2004). Additional strengths of the study include the large sample size, recruitment through cases identified from the national cancer registry, availability of detailed risk factor information, as well as multiple EBV serological markers.

In summary, the majority of NPC risk factors were not found to be significantly associated with anti-EBNA1 IgA positivity, the strongest predictor of NPC risk in our study population. In conclusion, our data suggest that non-viral NPC risk factors affect NPC risk via mechanisms other than through effects on EBV reactivation or host antibody responses to such infections.

\section{ACKNOWLEDGEMENTS}

We thank the NPC Study team and study participants for making this study possible. We also thank Ruth Pfeiffer and Fatma Shebl for help with the analysis. This study was supported by the Intramural Research Program of the National Cancer Institute, National Institutes of Health.
IARC (2004) Betel-quid and Areca-nut Chewing and Some Areca-nut-derived Nitrosamines. Vol. 85. IARC: Lyon

Jeng JH, Ho YS, Chan CP, Wang YJ, Hahn LJ, Lei D, Hsu CC, Chang MC (2000) Areca nut extract up-regulates prostaglandin production, cyclooxygenase-2 mRNA and protein expression of human oral keratinocytes. Carcinogenesis 21(7): 1365-1370

Jeng JH, Wang YJ, Chiang BL, Lee PH, Chan CP, Ho YS, Wang TM, Lee JJ, Hahn LJ, Chang MC (2003) Roles of keratinocyte inflammation in oral cancer: regulating the prostaglandin E2, interleukin- 6 and TNF-alpha production of oral epithelial cells by areca nut extract and arecoline. Carcinogenesis 24(8): $1301-1315$

Ji MF, Wang DK, Yu YL, Guo YQ, Liang JS, Cheng WM, Zong YS, Chan KH, Ng SP, Wei WI, Chua DT, Sham JS, Ng MH (2007) Sustained elevation of Epstein-Barr virus antibody levels preceding clinical onset of nasopharyngeal carcinoma. Br J Cancer 96(4): 623-630 
Ng WT, Choi CW, Lee MC, Law LY, Yau TK, Lee AW (2010) Outcomes of nasopharyngeal carcinoma screening for high risk family members in Hong Kong. Fam Cancer 9(2): $221-228$

Pfeiffer RM, Hildesheim A, Gail MH, Pee D, Chen CJ, Goldstein AM, Diehl SR (2003) Robustness of inference on measured covariates to misspecification of genetic random effects in family studies. Genet Epidemiol 24(1): 14-23

Pickard A, Chen CJ, Diehl SR, Liu MY, Cheng YJ, Hsu WL, Sun B, Hsu MM, Chen IH, Chen JY, Yang CS, Mittl BL, Chou SP, Ruggles DD, Goldstein AM, Hildesheim A (2004) Epstein-Barr virus seroreactivity among unaffected individuals within high-risk nasopharyngeal carcinoma families in Taiwan. Int J Cancer 111(1): 117-123

Shao YM, Poirier S, Ohshima H, Malaveille C, Zeng Y, de The G, Bartsch H (1988) Epstein-Barr virus activation in Raji cells by extracts of preserved food from high risk areas for nasopharyngeal carcinoma. Carcinogenesis 9(8): $1455-1457$

Yang XR, Diehl S, Pfeiffer R, Chen CJ, Hsu WL, Dosemeci M, Cheng YJ, Sun B, Goldstein AM, Hildesheim A (2005) Evaluation of risk factors for nasopharyngeal carcinoma in high-risk nasopharyngeal carcinoma families in Taiwan. Cancer Epidemiol Biomarkers Prev 14(4): $900-905$

Yu KJ, Hsu WL, Chiang CJ, Cheng YJ, Pfeiffer RM, Diehl SR, Goldstein AM, Gravitt PE, Chen CJ, Hildesheim A (2009) Cancer patterns in nasopharyngeal carcinoma multiplex families in Taiwan. Int J Cancer 124(7): $1622-1625$

Yu KJ, Hsu WL, Pfeiffer RM, Chiang CJ, Wang CP, Lou PJ, Cheng YJ, Gravitt P, Diehl SR, Goldstein AM, Chen CJ, Hildesheim A (2011) Prognostic utility of anti-EBV antibody testing for defining NPC risk among individuals from high-risk NPC families. Clin Cancer Res 17(7): $1906-1914$

Zeng Y, Zhang LG, Wu YC, Huang YS, Huang NQ, Li JY, Wang YB, Jiang MK, Fang Z, Meng NN (1985) Prospective studies on nasopharyngeal carcinoma in Epstein-Barr virus IgA/VCA antibody-positive persons in Wuzhou City, China. Int J Cancer 36(5): 545-547

Zeng Y, Zhong JM, Li LY, Wang PZ, Tang H, Ma YR, Zhu JS, Pan WJ, Liu YX, Wei ZN, Chen JY, Mo YK, Li EJ, Tan BF (1983) Follow-up studies on Epstein-Barr virus IgA/VCA antibody-positive persons in Zangwu County, China. Intervirology 20(4): 190-194

This work is published under the standard license to publish agreement. After 12 months the work will become freely available and the license terms will switch to a Creative Commons Attribution-NonCommercial-Share Alike 3.0 Unported License. 